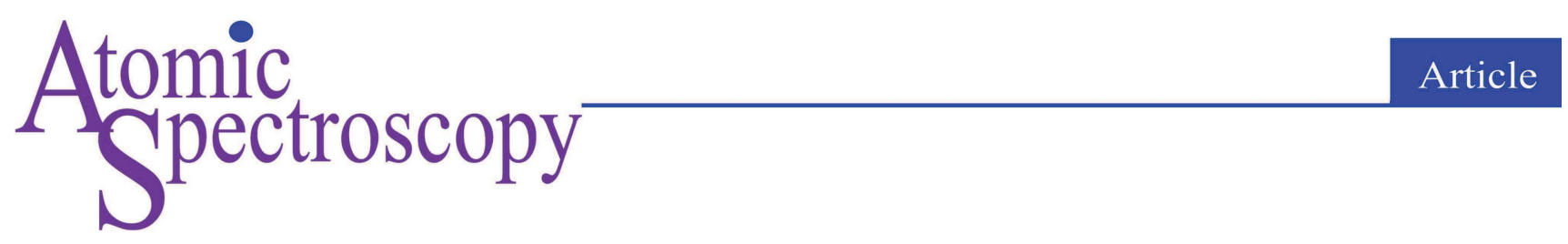

\title{
Direct Determination of Trace Iodine in Geological Samples by Solid Sampling Electrothermal Vaporization-Inductively Coupled Plasma Mass Spectrometry
}

\author{
Yu Cui, ${ }^{a}$ Lanlan Jin, ${ }^{a} *$ Huilai Li, ${ }^{a}$ Shenghong Hu, ${ }^{a}$ and Yuan Lian ${ }^{b}$ \\ a State Key Laboratory of Biogeology and Environmental Geology, School of Earth Sciences, China University of Geosciences, Wuhan 430074, P. R. \\ China

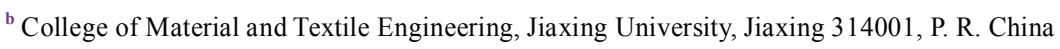

Received: Mar. 24, 2020; Revised: Apr. 15, 2020; Accepted: Apr. 15, 2020; Published: Apr.20, 2020.

ABSTRACT: The determination of iodine is of great importance for eco-environmental science and geosciences where fast analytical procedures are required for routine analysis. A procedure for high throughput determination of trace iodine in geological materials by solid sampling electrothermal vaporization-inductively coupled plasma mass spectrometry (SS-ETV-ICP-MS) was investigated. The transport system was refitted to obtain the best possible signal of iodine. The effect of particle size on the signal was investigated by an orthogonal experiment. As a result, the samples were ground before each test. To prevent loss of analyte in the ashing step, $4 \mu \mathrm{g}$ of $\mathrm{Pd}\left(\mathrm{NO}_{3}\right)_{2}$ and $40 \mu \mathrm{g}$ of ascorbic acid were added as a chemical modifier into the porous carbon boat before the procedure started. Subsequently, $200 \mu \mathrm{g}$ of sodium citrate was used in the pyrolysis process to improve the transfer and the ionization efficiency of iodine. The matrix-matched external calibration curves were established for soil and sediment, respectively, except rock was quantified by using standard solutions. The detection limits of rock, soil and sediment were $11 \mathrm{ng}$ $\mathrm{g}^{-1}, 9 \mathrm{ng} \mathrm{g}^{-1}$ and $8 \mathrm{ng} \mathrm{g}^{-1}$, respectively. The proposed method was used to analyze geological SRMs, and the accurate results obtained for iodine confirmed that it has great potential for the analysis of trace iodine in geological materials, including high sample throughput of 12-15 min per determination.

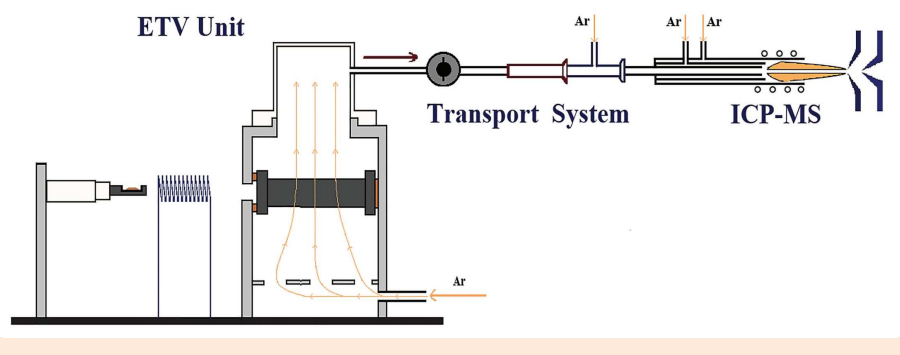

\section{INTRODUCTION}

Iodine (I) is a halogen element widely existing in nature, and it constantly circulates within the atmosphere, hydrosphere, biosphere and lithosphere. ${ }^{1,2}$ Because of the biological effects of iodine, it plays an important role in the process of substance exchange in the human organism and is a key indicator in the evaluation of the regional geochemical environment., ${ }^{3,4}$ In addition, iodine is also used for tracing the migration and enrichment of many metallic ore-forming elements in their mineralization. ${ }^{5,6}$ However, most environmental and geological materials have very low I content, only $1.4 \mathrm{mg} \mathrm{kg}^{-1}$ in the earth's crust. ${ }^{1}$ It is, therefore, a challenging task to determine I.

Different techniques have been used for the determination of iodine over the past decades. ${ }^{7-12}$ Inductively coupled plasma mass spectrometry (ICP-MS), a powerful technique for the rapid and accurate elemental analysis with ultra-trace level detection capability, has been used to determine the concentration of iodine with high sensitivity. ${ }^{13-16}$ Due to the properties of iodine, fluctuations of the signal, memory effects, poor analytical precision and accuracy occur during ICP-MS analysis. ${ }^{17}$ An appropriate pretreatment of the samples and a proper medium are key for the accurate determination of iodine. ${ }^{18-21}$ Strong oxidizing agents (e.g. $\mathrm{HClO}_{4}$ or $\mathrm{HNO}_{3}$ ) have been used to oxidize the volatile iodine to nonvolatile iodate in order to reduce iodine loss, ${ }^{22,23}$ but this can cause severe memory effects in the introduction system. Digestion/extraction with an alkaline solution (e.g. ammonia) is also an effective way to avoid iodine loss and suppress memory effects, ${ }^{17,24-26}$ and the purity of alkaline reagents required is difficult to meet 
for trace analysis. Capture devices are universal units used for preconcentration of I before determination, ${ }^{27-29}$ but they are complex operations and time-consuming. Therefore, the development of direct solid sampling methods is one of the effective means to solve these problems for low level iodine determination.

Electrothermal vaporization (ETV) is a novel sampling technology that offers several advantages, e.g. matrix separation, less interference, high sample conversion, use of small sample amount. ${ }^{30}$ Since the analyte has been conveniently separated from the sample matrix prior to introduction, the rapid and sensitive analysis of trace and ultra-trace elements is expected. Resano et al. ${ }^{31}$ evaluated the possibilities of ETV-ICP-MS for the direct determination of iodine at the ppm and sub-ppm level in biological materials. The potential of the technique for inorganic samples was also evaluated with a soil material. Kataoka et al. ${ }^{32}$ demonstrated the simultaneous determination of bromine and iodine in biological and aqueous samples using tetramethylammonium hydroxide solution as a chemical modifier for ETV-ICP-MS with a tungsten boat furnace vaporizer. Hence, solid sampling ETV-ICP-MS has been proven to be capable of the determination of trace iodine in biological materials. Compared with biological samples, geological samples are more diverse and their matrix is more complex, which further complicates the analysis of trace iodine by ETV-ICP-MS.

The object of this work is to develop a robust and high-throughput method based on SS-ETV-ICP-MS for the quantitative determination of trace iodine in geological materials. To achieve the best performance, the main parameters involving carrier gas and makeup gas flow, sample particle size and the effects of modifiers on iodine in the furnace were evaluated.

\section{Experimental}

Instrumentation. All experiments were carried out using a DCD-200 electrothermal vaporizer (Beijing Titan Instruments Co., Ltd., P.R. China) coupled to an Agilent 7700x inductively coupled plasma mass spectrometer (Agilent Technologies Inc., USA), as shown in Fig. 1A. A self-made quartz tube was fitted to connect the PTFE transfer tube $(6 \mathrm{~mm}$ i.d.) from the ETV and the ICP torch. The sampling boat and the vaporizer are made of porous carbon to enable high thermal conductivity and low background. A microbalance (OHAUS CP214, USA) with a readability of $0.1 \mathrm{mg}$ was used to weigh the samples.

Reagents and standard materials. All chemicals used were at least analytical pure grade, purchased from Sinopharm Chemical Reagent Co., Ltd. (Shanghai, P.R. China), except 1\% palladium nitrate from PerkinElmer, Inc. (USA). To reduce the blank testing value, commercially available nitric acid and hydrochloric acid were purified, respectively, by sub-boiling in a two-bottle Teflon still (Savillex Corporation, USA). Potassium iodate, potassium iodide and 1\% ascorbic acid solution were prepared daily. A 5\% solution of the ammonium hydroxide was used for cleaning the vaporization chamber. The solutions used in this study were prepared with $18.2 \mathrm{M} \Omega-\mathrm{cm}$ ultra-pure water produced with a water purification system (90005-02, Labconco WaterPro PS, USA). Different geological standard reference materials (SRMs) from the Institute of Geophysical and Geochemical Exploration (IGGE, Langfang, P.R. China) were analyzed as samples in this study. The materials investigated were: GBW07104 quartz hornblende andesite, GBW07107 shale, GBW07108 argillaceous limestone; GBW07426 soil, GBW07447 soil, GBW07448 soil, GBW07449 soil, GBW07450 soil, GBW07455 soil, GBW07303a stream sediment, GBW07307a stream sediment,

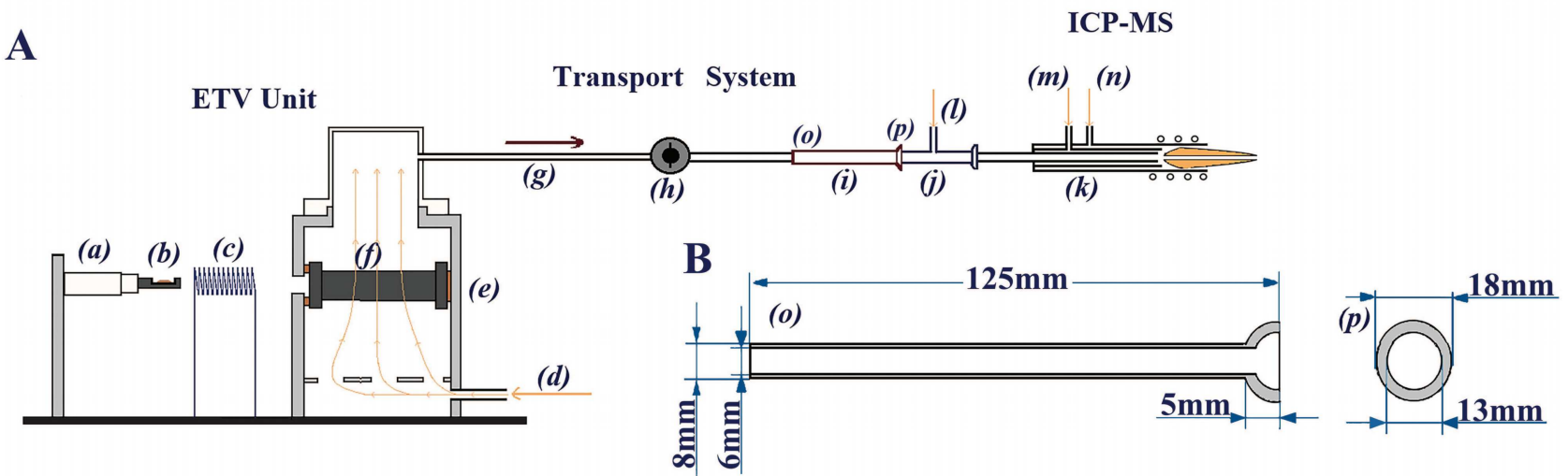

Fig. 1 (A) Schematic diagram of ETV-ICP-MS: (a) sampling arm, (b) sampling boat, (c) asher, (d) carrier gas (Ar), (e) electrothermal evaporation chamber, (f) vaporizer, ( $g$ ) PTFE transfer tube (6 mm i.d.), (h) manual valve, (i) self-made quartz connector, $(j)$ makeup gas tube, $(k)$ ICP torch, $(l)$ makeup gas (Ar), $(m)$ auxiliary gas (Ar), $(n)$ plasma gas (Ar); (B) Schematic representation of quartz connector: $(o)$ side view of the quartz connector, (p) cross-sectional view of the concave spherical grinding mouth. 
Table 1. Instrumental Operating Conditions for ET V-ICP-MS

\begin{tabular}{|c|c|c|}
\hline \multicolumn{3}{|c|}{ 7700x ICP-MS } \\
\hline RF power, W & \multicolumn{2}{|c|}{$1550 \mathrm{~W}$} \\
\hline Plasma gas flow rate, $\mathrm{L}$ min $^{-1}$ & \multicolumn{2}{|c|}{15} \\
\hline Carrier gas flow rate, $\mathrm{L} \mathrm{min}^{-1}$ & \multicolumn{2}{|c|}{0.6} \\
\hline Auxiliary gas flow rate, $L$ min $^{-1}$ & \multicolumn{2}{|c|}{1} \\
\hline Makeup gas flow rate, $\mathrm{L} \mathrm{min}^{-1}$ & \multicolumn{2}{|c|}{0.5} \\
\hline Dwell time, ms & \multicolumn{2}{|c|}{10} \\
\hline Reading per replicate & \multicolumn{2}{|c|}{3} \\
\hline Data collection mode & \multirow{2}{*}{\multicolumn{2}{|c|}{$\begin{array}{l}\text { Peak hopping } \\
{ }^{127} \mathrm{I}\end{array}$}} \\
\hline Signal monitored & & \\
\hline \multicolumn{3}{|c|}{ DCD-200 Electrothermal Vaporizer } \\
\hline Sample mass & \multicolumn{2}{|l|}{$2.0 \mathrm{mg}$} \\
\hline KI standard solution ${ }^{a}$ & \multicolumn{2}{|c|}{$2 \mu \mathrm{L}\left(1 \mu \mathrm{g} \mathrm{mL} L^{-1}\right)$} \\
\hline & \multicolumn{2}{|c|}{ Pre-reduced Pd: $4 \mu \mathrm{g}$ of } \\
\hline Chemical modifiers & \multicolumn{2}{|c|}{$\begin{array}{l}\mathrm{Pd}\left(\mathrm{NO}_{3}\right)_{2} \text { and } 40 \mu \mathrm{g} \text { of } \\
\text { ascorbic acid used in ashing } \\
\text { step }\end{array}$} \\
\hline & \multirow{2}{*}{\multicolumn{2}{|c|}{$\begin{array}{l}200 \mu \mathrm{g} \text { of sodium citrate } \\
\text { used in pyrolysis step }\end{array}$}} \\
\hline & & \\
\hline \multicolumn{3}{|c|}{ Vaporization Procedure } \\
\hline & Time (s) & Power (W) \\
\hline \multicolumn{3}{|c|}{ Addition of $\mathrm{Pd}\left(\mathrm{NO}_{3}\right)_{2}$ and ascorbic acid } \\
\hline Drying ${ }^{b}$ & 150 & 30 \\
\hline Pd reduced step & 10 & 50 \\
\hline \multicolumn{3}{|l|}{ Addition of solid samples } \\
\hline Ashing & 90 & 90 \\
\hline \multicolumn{3}{|l|}{ Addition of sodium citrate } \\
\hline Drying & 90 & 30 \\
\hline Pyrolysis & 20 & 50 \\
\hline Vaporization & 15 & 140 \\
\hline Cleaning & 13 & 150 \\
\hline
\end{tabular}

${ }^{\mathrm{a}}$ The standard solution was used to optimize the parameters.

${ }^{\mathbf{b}}$ The drying step was carried out twice, corresponding to the addition of $\mathrm{Pd}(\mathrm{NO} 3)_{2}$ and ascorbic acid in two separate times.

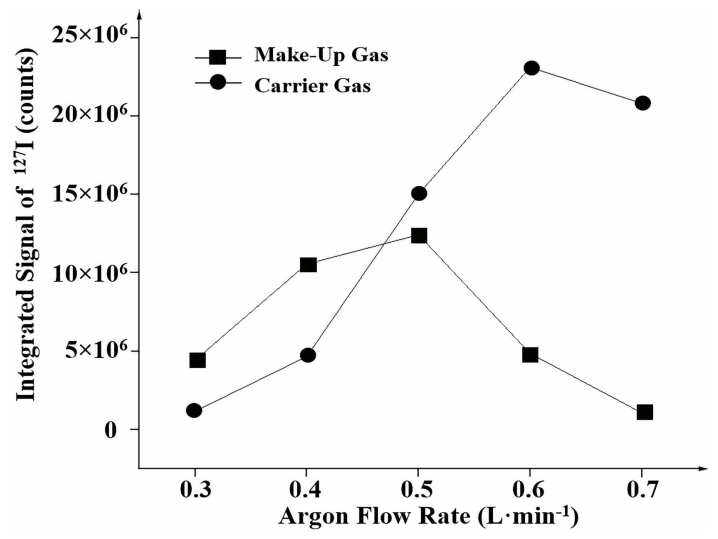

Fig. 2 Effect of argon flow rate on integrated intensity of iodine. These experiments were carried out using the KI standard solution with the standard procedure of the ETV.

GBW07308 stream sediment, GBW07309 stream sediment, GBW07311 stream sediment, GBW07366 stream sediment. All of the sample powders were further ground with zirconia beads at $6000 \mathrm{r} \mathrm{min}^{-1}$ in $90 \mathrm{~s}$ by a cell breaker (Wuhan Liyuan Zongke Bio-Tech Co., Ltd.) before the experiment.
Procedure. Prior to sample analysis, $2 \mu \mathrm{L}$ of $1 \%$ palladium nitrate solution and $2 \mu \mathrm{L}$ of $1 \%$ ascorbic acid solution were added twice into the sampling boat separately. After drying twice at $30 \mathrm{~W}$ for $150 \mathrm{~s}$, Pd was pre-reduced by heating the boat in the vaporizer at $50 \mathrm{~W}$ for $10 \mathrm{~s}$. Then the solution was cooled down to room temperature, $2.0 \mathrm{mg}$ of the sample was directly weiged into the boat and ashed at $90 \mathrm{~W}$ for $90 \mathrm{~s}$. Subsequently, $2 \mu \mathrm{L}$ of $10 \%$ sodium citrate solution was added and dried at $30 \mathrm{~W}$ for $90 \mathrm{~s}$. The sampling boat was inserted into the vaporizer again and pyrolyzed in inert atmosphere at $50 \mathrm{~W}$ for $20 \mathrm{~s}$. Finally, the vaporization and cleaning steps were finished in the vaporizer. All of the drying and ashing steps were operated in the asher made of $\mathrm{Ni}-\mathrm{Cr}$ heating coil. The operating conditions are summarized in Table 1.

\section{Results and Discussion}

Optimization and working conditions. The solid aerosols produced by ETV were directly introduced into the ICP plasma, thus the connector between them was redesigned to replace the traditional sample introduction system (nebulizer and spray chamber). A quartz tube with a concave spherical grinding mouth on one end was designed to connect the PTFE transfer tube (6 mm i.d.) from the ETV and the ICP torch. The specific size of this quartz tube is shown in Fig. 1B. In order to ensure air tightness, a clamp was used to increase the seamless connection between the concave spherical mouth of the quartz tube and the convex spherical mouth of the ICP torch.

Due to the entering of the ETV carrier flow, the stability of the ICP plasma was disturbed, which also affected the precision of the signal. The built-in dilution gas of the 7700x ICP-MS as makeup gas was used to stabilize the plasma. The flow rate of the carrier gas and makeup gas were optimized to assure efficient transport of the analyte to the ICP and the stability of the plasma. The effect of these two flow rates on the iodine signal intensity is shown in Fig. 2. Finally, $0.6 \mathrm{~L} \mathrm{~min}^{-1}$ carrier gas and $0.5 \mathrm{~L} \mathrm{~min}^{-1}$ makeup gas were used throughout. To prevent plasma instability caused by the introduction of air during sample replacement, a manual valve with a switch was inserted at the front of the self-made quartz connector. It was closed when the sample was replaced and should be opened slowly after the sample is added in order to avoid extinction of the plasma due to the sudden entry of a large flow of gas. Meanwhile, the original NBR (nitrile rubber buna) gaskets were replaced with high temperature-resistant Teflon materials to improve the air tightness of the ETV.

Effect of sample particle size. Electrothermal vaporization is a kind of micro-sampling technology, whose sample amount is usually dozens of micrograms to milligrams, and the representativeness and homogeneity of the samples directly affect the accuracy and precision of the analytical results. Commonly, limited due to the uniformity of the bottles, the 

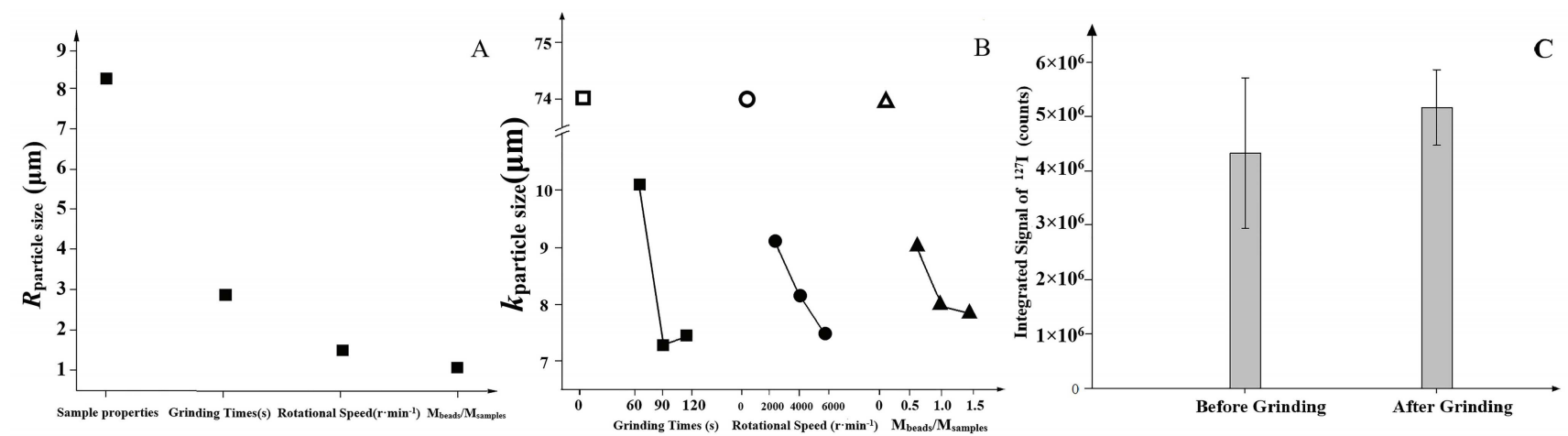

Fig. 3 Results of orthogonal experiment for particle size, (A) Range analysis $\left(R_{\text {particle size }}\right)$, (B) Average particle size $\left(k_{\text {particle size }}\right)$. (C) Effect of particle size on integrated intensity of iodine. The experiments were carried out using GBW07107 with standard procedure of ETV-ICP-MS. Error bars correspond to three measurements $\pm \mathrm{SD}$.
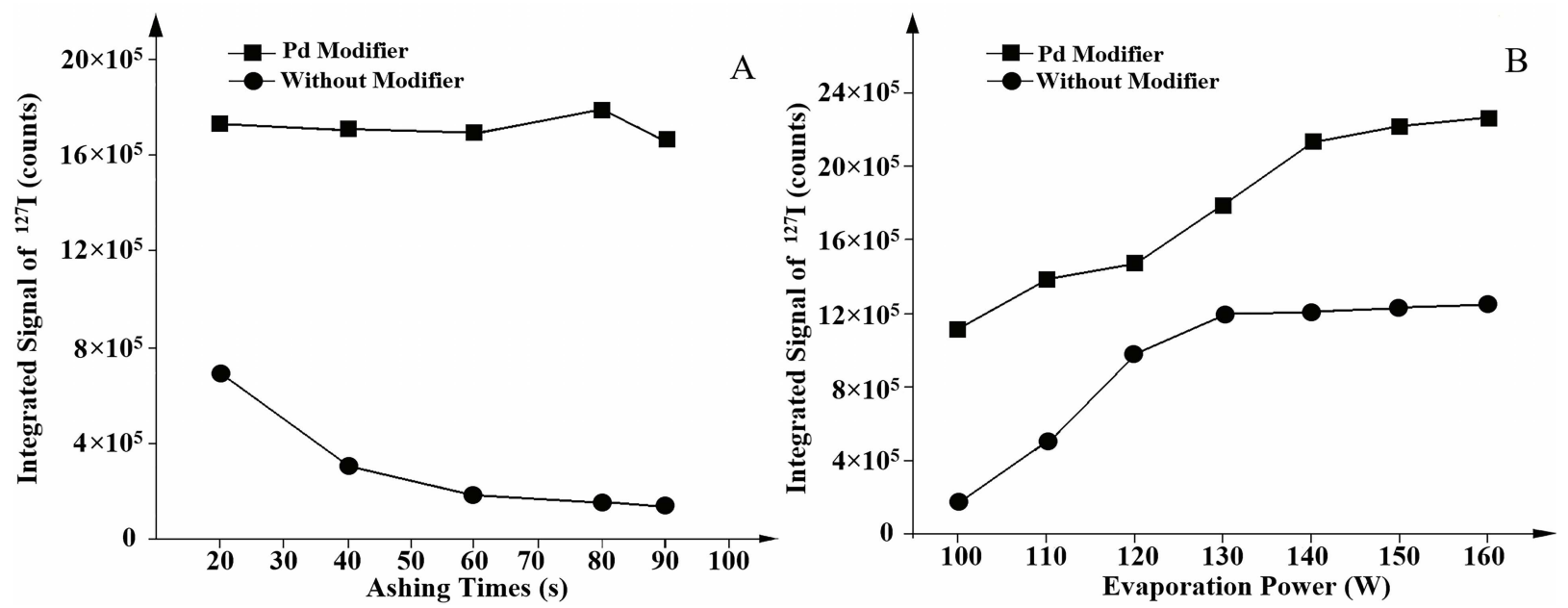

Fig. 4 Comparison of integrated signal of iodine with and without pre-reduced $\mathrm{Pd}\left(4 \mu \mathrm{g}\right.$ of $\left.\mathrm{Pd}\left(\mathrm{NO}_{3}\right)_{2}\right)$ using 2 ng $\mathrm{KI}$ during (A) the ashing process (evaporated at $120 \mathrm{~W}$ for $15 \mathrm{~s}$ ), (B) the vaporization process (ashed at $90 \mathrm{~W}$ for $90 \mathrm{~s}$ ).

nominal minimum sampling quantity available for SRMs is 0.1-0.2 g, which does not meet the requirements for micro-sampling. ${ }^{33}$ Reducing the particle size is an effective method to improve the homogeneity of the samples. In this study, zirconia abrasive beads were used to further grind the samples in a cell breaker, and the effects of grinding time, rotational speed, sample properties (three geological SRMs of GBW07104, GBW07107 and GBW07108) and mass of zirconia abrasive beads $\left(\mathrm{M}_{\text {beads }} / \mathrm{M}_{\text {samples }}\right)$ on particle size were investigated using an orthogonal test (Tables S1-S3). Although the sample properties had the greatest influence on an average particle size ( $\left.k_{\text {particle size }}\right)$ through the range analysis $\left(R_{\text {particle size }}\right)$ (Fig. $3 \mathrm{~A}$ ), the $k_{\text {particle size }}$ was decreased from $74 \mu \mathrm{m}$ to $<10 \mu \mathrm{m}$ at $6000 \mathrm{r} / \mathrm{min}$ for $90 \mathrm{~s}$ with $\mathrm{M}_{\text {beads }} / \mathrm{M}_{\text {samples }}=1.5$ in the geological SRMs (Fig. 3B). Meanwhile, comparing the signal intensity and standard deviation (SD) of iodine in the grounded sample (GBW07107) with those in ungrounded one (Fig. 3C), the evaporation efficiency of iodine (the signal intensity of iodine increased) and the precision were improved by minimizing the sample particle size.

Modifier performances. Iodine is a volatile element, and how to suppress the loss of iodine during pyrolysis is the basis of quantitative analysis. The research of Grünke ${ }^{34}$ and de Gois ${ }^{35}$ confirmed that the platinum group elements (PGE) in elemental form contribute to improving the thermal stability of volatile elements, and their function is better than compounds of PGE. In this study, the experiments were carried out using KI aqueous standards ( $2 \mathrm{ng}$ of $\mathrm{KI}$ ) with $4 \mu \mathrm{g}$ of $\mathrm{Pd}\left(\mathrm{NO}_{3}\right)_{2}$ reduced by $40 \mu \mathrm{g}$ of ascorbic acid to avoid premature iodine loss. Furthermore, the acid medium of $\mathrm{Pd}\left(\mathrm{NO}_{3}\right)_{2}$ solution may substantially enhance iodide volatility, its pre-reduction process was completed before the sample was added. According to Fig. $4 \mathrm{~A}$, the signal intensity without modifier declined with the ashing time, which indicated that iodine loss occurred in the 
Table 2. Results Obtained for the Determination of Iodine in Nine

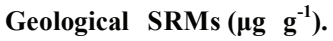

\begin{tabular}{lcc}
\hline Geological SRMs & SS-ETV-ICP-MS & Reference values \\
\hline GBW07104 & $0.16 \pm 0.03^{\mathrm{a}}$ & $(0.14)^{\mathrm{b}}$ \\
GBW07107 & $0.27 \pm 0.02$ & $0.24 \pm 0.06$ \\
GBW07108 & $0.21 \pm 0.02$ & $0.23 \pm 0.08$ \\
GBW07449 & $1.3 \pm 0.2$ & $1.4 \pm 0.4$ \\
GBW07450 & $0.79 \pm 0.20$ & $0.73 \pm 0.14$ \\
GBW07455 & $0.9 \pm 0.1$ & $1.1 \pm 0.2$ \\
GBW07303a & $1.9 \pm 0.3$ & $1.7 \pm 0.2$ \\
GBW07309 & $0.71 \pm 0.10$ & $0.63 \pm 0.09$ \\
GBW07311 & $2.1 \pm 0.2$ & $2.0 \pm 0.3$ \\
\hline
\end{tabular}

${ }^{a}$ The uncertainties are expressed as $95 \%$ confidence intervals, and each value consists of three consecutive measurements.

${ }^{\text {b }}$ This data is the recommended value.

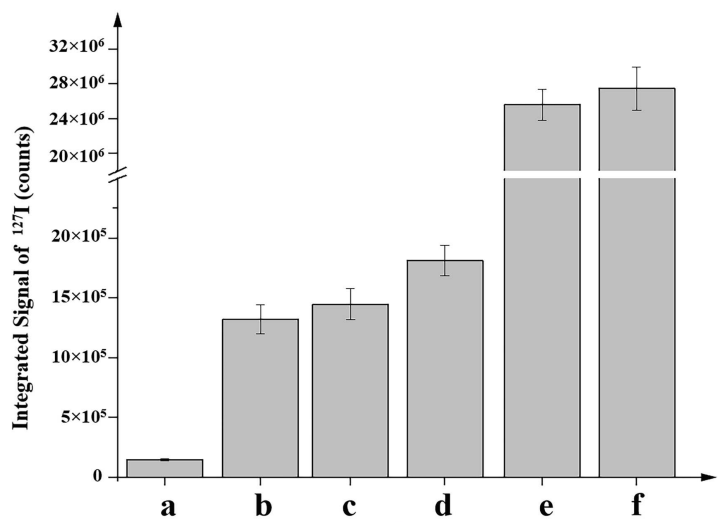

Fig. 5 Effect of sodium citrate on integrated intensity of iodine (2 $\mathrm{ng}$ of $\mathrm{KI})$. (a) Background; (b) reagent blank of $\mathrm{Pd}\left(\mathrm{NO}_{3}\right)_{2}$, ascorbic acid and sodium citrate; (c) $2 \mathrm{ng}$ of KI standard solution; (d) pre-reduced Pd (4 $\mu \mathrm{g}$ of $\left.\mathrm{Pd}\left(\mathrm{NO}_{3}\right)_{2}\right)$ and $2 \mathrm{ng}$ of $\mathrm{KI}$; (e) $200 \mu \mathrm{g}$ of sodium citrate and $2 \mathrm{ng}$ of KI; (f) pre-reduced $\mathrm{Pd}\left(4 \mu \mathrm{g}\right.$ of $\left.\mathrm{Pd}\left(\mathrm{NO}_{3}\right)_{2}\right), 200 \mu \mathrm{g}$ of sodium citrate and $2 \mathrm{ng}$ of KI. Error bars correspond to three measurements \pm SD.

ashing step, but it was significantly enhanced and remained stable in the whole ashing stage after introducing Pd. The signals obtained in the vaporization step without and with $\mathrm{Pd}$ are shown in Fig. 4B. The evaporation power increased from 130 to $140 \mathrm{~W}$ with the addition of $\mathrm{Pd}$, which demonstrated that the vaporization temperature of iodine increased as a result of I-Pd interaction. Therefore, pre-reduced Pd not only significantly prevents losses for iodine in the ashing step, but it also helps to improve the separation efficiency of iodine by reducing the influence of the matrix effect.

The high adsorption capacity of iodine because it's easily deposits on the wall of the vaporizer and the transfer system causes iodine loss and memory effects. In ETV-ICP-MS, the chemical modifier also plays an important role in improving transfer efficiency. ${ }^{36}$ Based on the analyte transport theory in ETV-ICP-MS from Kántor, ${ }^{37}$ Grégoire et $a l .{ }^{38}$ demonstrated that the $\mathrm{C}$ particles released from carbon-containing materials in the furnace were conducive to the formation of target aerosol particles, thus improving transport efficiency. In our work, $200 \mu \mathrm{g}$ of sodium citrate was used in the pyrolysis step and KI aqueous standards ( $2 \mathrm{ng}$ of $\mathrm{KI}$ ) were used under the optimum operating conditions. As is shown in Fig. 5, the signal intensity of iodine increased by an order of magnitude with sodium citrate. We found that sodium citrate not only improved the transport efficiency of iodine, but also enhanced the ionization efficiency of iodine due to the charge transfer of carbon in the plasma. ${ }^{39-41}$ Under these circumstances, the use of pre-reduced $\mathrm{Pd}$ and carbon-producing reagents (sodium citrate) were found to be essential for quantitative analysis of iodine by ETV-ICP-MS.

Analysis of Geological SRMs. The matrix of geological samples is complex and diverse. Although ETV-ICP-MS is useful for separating the analyte from the matrix, it is almost impossible to remove most of the refractory constituents. Hence, the influence of matrix effects cannot be ruled out. In order to obtain the calibration curve with a corresponding matrix, six geological SRMs with different concentrations were used: GBW07426, GBW07447 and GBW07448 for soils, GBW07307a, GBW07308 and GBW07366 for sediments. However, since not enough standard materials of known iodine concentrations in rocks are available, this lack needs to be investigated and studied in further work. Good correlation between signal intensity (peak area) and concentrations of iodine were obtained. In this way, the concentration of iodine in geological samples could be quantitatively determined. The analytical results of iodine in a series of geological SRMs were listed in Table 2, and all were found to be in good agreement with the certified or recommended values, with the \% RSD in the vicinity of $10 \%$. The limits of quantification (LOQs) for rocks, soils and stream sediments analyzed in this work, estimated as the concentration equivalent to 10 times the SD of 11 consecutive measurements of the blank, were $11 \mathrm{ng} \mathrm{g}^{-1}, 9 \mathrm{ng}$ $\mathrm{g}^{-1}$ and $8 \mathrm{ng} \mathrm{g}^{-1}$, respectively.

\section{CONCLUSIONS}

The direct determination of trace iodine in geological materials using solid sampling electrothermal vaporization-ICP-MS was demonstrated based on an optimized transmission system. Pre-reduced Pd was used to prevent loss of iodine during the ashing processes and sodium citrate was added to improve the transfer efficiency and the degree of ionization of iodine. The analytical performance and sample throughput (12-15 min per analysis) of iodine in geological samples were significantly improved by the present procedure. According to the evaluation of geological reference materials, which included rocks, soils and stream sediments, the method shows great potential for routine analysis of trace iodine in geological materials with sufficient sensitivity, precision and accuracy. 


\section{ASSOCIATED CONTENT}

Please contact the corresponding author for Supporting Information. Table S1, Factors and levels of orthogonal experiment for particle size; Table S2, Lists of $L_{9}\left(3^{4}\right)$ orthogonal experiment; Table $\mathrm{S} 3, k_{\text {particle size }}$ and $R_{\text {particle size }}$ of the orthogonal experiment for particle size.

\section{AUTHOR INFORMATION}

\section{Corresponding Author}

*L.L Jin.

Email address: annj11@163.com

Notes

The authors declare no competing financial interest.

\section{ACKNOWLEDGMENTS}

The authors are grateful for the financial support from the National Natural Science Foundation of China (NSFC No. 41703132, 21565013) and the Science and Technology Program of Zhejiang Province (No. LGC20B050014). The authors give thanks to the State Key Laboratory of Biogeology and Environmental Geology for its support.

\section{REFERENCES}

1. L. L. He, Master Dissertation, Nanchang University, Nanchang, P.R. China, 2012.

2. R. Fuge and C. C. Johnson, Appl. Geochem., 2015, 63, 282-302.

3. X. B. Xue, J. X. Li, K. Qian and X. J. Xie, Sci. China Earth Sci., 2018, 43, 910-921.

4. K. Miwa, H. Obata and T. Suzuki, J. Nucl. Sci. Technol., 2020, 5, 537-545.

5. Z. L. Lu, S. T. Hummel, L. K. Lautz, G. D. Hoke, X. L. Zhou, J. Leone and D. I. Siegel, Appl. Geochem., 2015, 60, 29-36.

6. L.H. Ji, G. S. Liu, Y. P. Huang, N. Xing and Z. G. Chen, Acta Oceanol. Sin., 2015, 34, 13-19.

7. K. Ito, Anal. Chem., 1997, 69, 3628-3632.

8. N. Choengchan, K. Uraisin, K. Choden, W. Veerasai, K. Grudpan and D. Nacapricha, Talanta, 2002, 58, 1195-1201.

9. K. Reddy-Noone, A. Jain and K. K. Verma, J. Chromatogr. A, 2007, 1148, 145-151.

10. Z. P. Huang, Q. Subhani, Z.Y. Zhu, W. Q. Guo and Q. Zhu, Food Chem., 2013, 139, 144-148.

11. T. Wang, W. M. Lin, X. L. Dai, L. J. Gao, B. Wang and D. Q. Quan, J. Chromatogr. Sci., 2015, 53, 280-284.

12. M. Nosuhi and A. Nezamzadeh-Ejhieh, J. Electroanal. Chem., 2018, 810, 119-128.

13. H. Baumman, Fresen. J. Anal. Chem., 1990, 338, 809-812.

14. C. A. Hartwig, I. G. Toralles, M. G. Crizel, A. L. H. Muller, R. S. Picoloto, E. M. M. Flores and M. F. Mesko, Anal. Methods, 2014,
6, 7540-7546.

15. V. C. Costa, R. S. Picoloto, C. A. Hartwig, P. A. Mello, E. M. M. Flores and M. F. Mesko, Anal. Bioanal. Chem., 2015, 407, 7957-7964.

16. W. Guo, Y. X. Wang, J. X. Li, Y. E. Peng, L. L. Jin, Q. H. Guo and S. H. Hu, At. Spectrosc., 2016, 85, 7-12.

17. B. Li, H. L. He, S. Y. Shi, X.R. Ma, H. L. Wen and C. F. Lu, Rock Mineral Anal., 2001, 20, 161-166.

18. G. Knapp, B. Maichin, P. Fecher, S. Hasse and P. Schramel, Fresen. J. Anal. Chem., 1998, 362, 508-513.

19. J. A. Nobrega, M. C. Santos, R. A. de Sousa, S. Cadore, R.M. Barnes and M. Tatro, Spectrochim. Acta B, 2006, 61, 465-495.

20. M. F. Mesko, V. C. Costa, R.S. Picoloto, C. A. Bizzi and P. A. Mello, J. Anal. At. Spectrom., 2016, 31, 1243-1261.

21. D. L. Novo, R. M. Pereira, A. S. Henn, V. C. Costa, E. M. M. Flores and M. F. Mesko, Anal. Chim. Acta, 2019, 1060, 45-52.

22. E. H. Larsen and M. B. Ludwigsen, J. Anal. At. Spectrom., 1997, 12, 435-439.

23. G. Radlinger and K. G. Heumann, Anal. Chem., 1998, 70, 2221-2224.

24. J. A. Nobrega, M. C. Santos, R. A. de Sousa, S. Cadore, R.M. Barnes and M. Tatro, Spectrochim. Acta B, 2006, 61, 465-495.

25. Z. Ezerinskis, A. Spolaor and T. Kirchgeorg, J. Anal. At. Spectrom., 2014, 29, 1827-1834.

26. L. Luo, Q. Shuai, L. L. Jin and S. H. Hu, At. Spectrosc., 2019, 40, 63-68.

27. B. Schnetger, Y. Muramatsu and S. Yoshida, Geostand. Newsl., 1998, 22, 181-186.

28. G. B. Souza, E. N. V. M. Carrilho, C. V. Oliveira, A. R. A. Nogueira and J. A. Nobrega, Spectrochim. Acta B, 2002, 57, 2195-2201.

29. H. Fujiwara, K. Kawabata, J. Suzuki and S. Osamu, J. Anal. At. Spectrom., 2011, 26, 2528-2533.

30. Y. Zhang, Z. Jiang and B. Hu, Rapid Commun. Mass Spectrom., 2006, 20, 2091-2097.

31. M. Resano, E. Garcia-Ruiz, L. Moens and F. Vanhaecke, J. Anal. At. Spectrom., 2005, 20, 81-87.

32. H. Kataoka, S. Tanaka, C. Konishi, Y. Okamoto, T. Fujiwara and K. Ito, Rapid Commun. Mass Spectrom., 2008, 22, 1792-1798.

33. X. F. Mao, PhD Dissertation, Chinese Academy of Agricultural Sciences, Beijing, P.R. China, 2015.

34. K. Grünke, H. J. Stärk, R. Wennrich, H.M. Ortner and J. A. C. Broekaert, Fresen. J. Anal. Chem., 1997, 359, 465-468.

35. J. S. de Gois, E. R. Pereira, B. Welz and D. L. G. Borges, Spectrochim. Acta B, 2015, 105, 12-17.

36. M. Aramendia, M. Resano and F. Vanhaecke, Anal. Chim. Acta, 2009, 648, 23-44.

37. T. Kántor, Spectrochim. Acta B, 1988, 43, 1299-1320.

38. D. C. Grégoire and R. E. Sturgeon, Spectrochim. Acta B, 1993, 48, 1347-1364.

39. W. Guo, S. H. Hu, X. F. Li, J. Zhao, S. S. Jin, W. J. Liu and H. F. Zhang, Talanta, 2011, 84, 887-894.

40. W. Guo, S. H. Hu, X. J. Wang, J. Y. Zhang, L. L. Jin, Z. L. Zhu and H.F. Zhang, J. Anal. At. Spectrom., 2011, 26, 1198-1203.

41. W. Guo, S. H. Hu, Y. X. Wang, L. Y. Zhang, Z. C. Hu and J. Y. Zhang, Microchem. J., 2013, 108, 106-112. 